\title{
OS DESAFIOS DO PLANEJAMENTO E GESTÃO URBANOS EM PEQUENAS CIDADES DE MINAS GERAIS.
}

\author{
Ítalo Itamar Caixeiro Stephan ${ }^{1}$
}

Ana Cristina de Souza Maria ${ }^{2}$

\begin{abstract}
RESUMO
Este texto é uma síntese da realidade baseada em fontes de contato direto com dezenas de cidades do Estado de Minas Gerais, como a experiência da prática da oferta de curso de especialização em planejamento urbano e da a avaliação do desenvolvimento de planos diretores. Ele é ainda apoiado na investigação da avaliação da implementação de planos diretores; nas assessorias em planejamento e em pesquisas sobre o planejamento urbano e regional e sobre a caracterização de pequenas cidades. As pequenas cidades mineiras estão em uma posição em que o planejamento urbano não é um componente tratado com a atenção necessária na gestão urbana, que continua separado do planejamento e onde o crescimento urbano descontrolado tem agravado problemas, como dificuldades na oferta de serviços públicos e no agravamento dos impactos socioambientais. Para enfrentar esses desafios, destacamos a importância de alguns aspectos serem desenvolvidos, como a utilização do conhecimento produzido nas instituições federais de ensino, a criação de consórcios municipais e o desenvolvimento do planejamento regional.
\end{abstract}

PALAVRAS-CHAVE: Planejamento urbano, pequenas cidades, Minas Gerais.

\section{THE CHALLENGES OF PLANNING AND MANAGEMENT IN URBAN SMALL CITIES OF GENERAL MINES.}

\section{SUMMARY}

This text is a synthesis of grounded reality in direct contact sources with dozens of cities of the state, such as the experience of the practices such as the offering of specialization course in urban planning or the assessment of development of director plans. It is further supported on research aimed at evaluation of the implementation of director plans; in given advising in urban planning and on the research on regional planning and characterization of small towns of Minas Gerais, Brazil. The small cities of the state are in a position where the urban planning is not a component treated with the necessary attention in the urban management, that remains separated from planning and in which the uncontrolled urban growth has exacerbating problems in offering of public services and worsening of

\footnotetext{
${ }^{1}$ Arquiteto e Urbanista, Universidade Federal de Viçosa, Professor, stephan@ufv.br. 2 Geógrafa, Mestranda Arquitetura e Urbanismo, Universidade Federal de Viçosa, ana.c.maria@ufv.br
} 
Revista Nacional de

Gerenciamento de Cidades

environmental impacts. To meet these challenges we point out the importance of some forms to be developed such as the use of the knowledge produced in federal educational institutions, the implementation of municipal consortiums and the development of regional planning.

KEYWORDS: urban planning, small towns, Minas Gerais, Brazil.

\title{
LOS RETOS DE PLANIFICACIÓN Y GESTIÓN EN URBANAS PEQUEÑOS MUNICIPIOS DE GENERAL minas.
}

\begin{abstract}
RESUMEN
Este texto es una síntesis de la realidad basada en formas de contacto directo con decenas de ciudades del estado, como la experiencia de la práctica de la oferta de cursos de especialización en la planificación urbana y la evaluación del desarrollo de los planes directores. También se apoya en la investigación sobre la evaluación de la aplicación de los planes directores; en el asesoramiento sobre la planificación y la investigación sobre la planificación urbana y regional y sobre la caracterización de las pequeñas ciudades de Minas Gerais. Los pequeños pueblos mineros se encuentran en una posición en que el urbanismo no es un componente tratado con la atención necesaria en la gestión urbana, que se mantiene separado de la planificación; en que el crecimiento urbano descontrolado está exacerbando problemas tales como dificultades en la prestación de los servicios públicos y el agravamiento de los impactos ambientales. Para afrontar estos retos, se destaca la importancia de ciertos aspectos que se desarrollarán como utilizando el conocimiento producido en las instituciones educativas federales; la creación de consorcios locales y el desarrollo de de planificación regional.
\end{abstract}

PALABRAS CLAVE: planificación urbana, ciudades pequeñas, Minas Gerais.

\section{Introdução: O planejamento e gestão urbanos das pequenas cidades}

Há quase uma década a geógrafa Ângela Maria Endlich nos alertava que "não contemplar as pequenas cidades é esquecer uma parte da realidade urbana", ao chamar atenção para a escassez de estudos, para uma negligência da academia (ENDLICH, 2006 p.29). A escassez ainda prevalece nos dias de hoje, e a importância desses estudos permanece indiscutível. O termo "pequenas cidades" adotado neste texto diz respeito a municípios de pequeno porte demográfico com população inferior aos cem mil habitantes, conforme classificação generalista do IBGE, embora para alguns autores, essa definição é mais precisa. Para Roberto Lobato Corrêa, as pequenas cidades são um universo muito variado quando 


\section{Revista Nacional de}

consideramos as características associadas aos seus núcleos urbanos e suas hinterlândias. Para o autor, as pequenas cidades dificilmente ultrapassam os 30 mil habitantes e representam nós minúsculos "em uma vasta e complexa rede urbana", que tiveram seus papeis nas relações urbano-rurais alterados, uma "refuncionalização" face à perda de seu papel nas relações com o campo (CORRÊA, 2011, p. 7), e isso representa para este artigo a maioria dos casos. Para tratar das condições do planejamento e gestão urbanos das pequenas cidades mineiras, partese do princípio geral que "no limiar do século XXI, quase todas as sociedades enfrentam a desanimadora perspectiva de uma infindável crise urbana, consequência de um modelo obsoleto e irracional da ocupação do espaço" (RATNER, 2009, p. 7). O "progresso" cantado por muitos parece trazer benefícios ilimitados e prosperidade para algumas cidades, mas, ao mesmo tempo, tende a produzir custos sociais, pouco visíveis no início, mas desastrosos para a população e o poder público em longo prazo. O desenvolvimentismo excludente, termo adotado por Vainer (2013), não é mais exclusivo das cidades grandes e médias, é visível nas pequenas: "favelização, informalidade, serviços precários ou inexistentes, desigualdades sociais profundas, degradação ambiental, violência urbana, congestionamentos e custos crescentes de um transporte público precário e espaços urbanos segregados" (VAINER, 2013, p. 39). São cabíveis outras reflexões de estudiosos como Maria de Nazaré Wanderley (2004), para quem o fato de ser pequeno frequentemente significa ser precário do ponto de vista dos recursos disponíveis. Há sinais visíveis em qualquer cidade pequena de que a forma de crescimento potencializa graves problemas ao meio ambiente, à qualidade de vida, à mobilidade e à identidade local. Tais sinais afetam diretamente a todos os seus moradores, pois eles passam a lidar com as dificuldades de circular nas ruas, com a degradação da qualidade ambiental das moradias, com a perda do patrimônio arquitetônico e com as enchentes causadas pela insuficiência de drenagem urbana. Até nas pequenas cidades, os moradores "indesejáveis" são deslocados para as periferias distantes, em conjuntos habitacionais longe dos locais de trabalho, a 


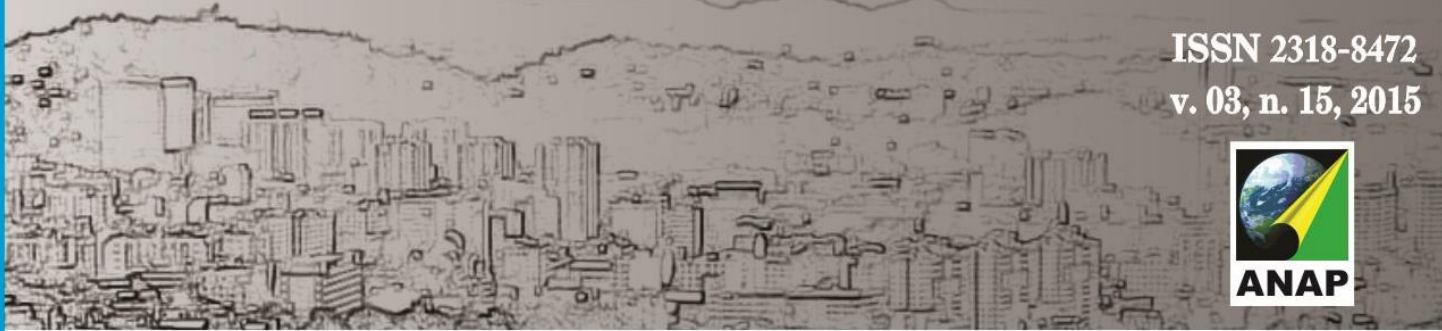

\section{Revista Nacional de} Gerenciamento de Cidades

custos monetários inacessíveis e com condições de transporte precaríssimas ou inexistentes.

Figura 1: Ponte Nova, MG - 59.814 habitantes (IBGE, 2014). Urbanização às margens do Rio Piranga, com enchentes, desmatamentos e incêndios.

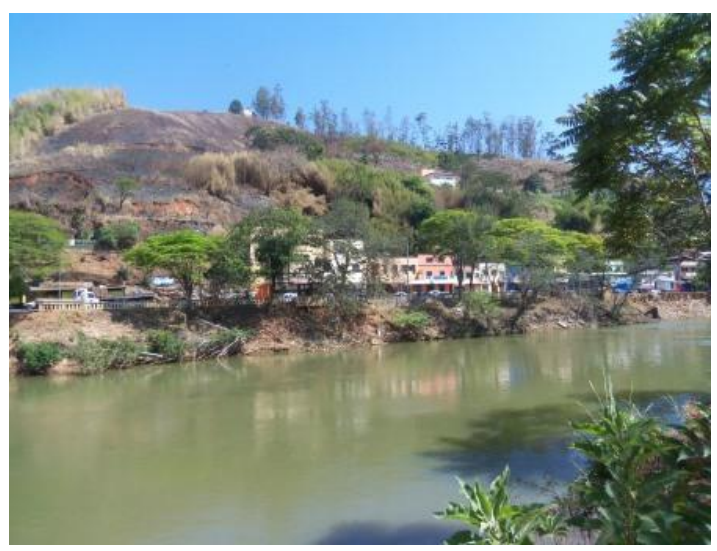

Fonte: Autores, 2014.

\section{Metodologia}

Este artigo discute acerca das pequenas cidades, em especial aquelas localizadas em um Estado de amplas dimensões e de contrastantes condições de desenvolvimento. Não é possível falar das 824 cidades mineiras com menos de cem mil habitantes. É possível, através de experiências diversas, conhecer as cidades para entender os seus papéis e significados atuais. Trata-se aqui de uma amostra, amparada no conhecimento adquirido por um grupo de pesquisadores sobre pelo menos 70 municípios, sendo apenas onze com mais de cinquenta mil habitantes, a partir do envolvimento de atividades como ensino de Pós-Graduação, elaboração de legislação urbana, pesquisas e projetos, conforme o Quadro 1. 


\section{Revista Nacional de}

Quadro 1 - Atividades desenvolvidas em cidades mineiras.

\begin{tabular}{|c|c|c|}
\hline Atividades & Municípios & Mesorregiões \\
\hline \multirow[t]{3}{*}{ Elaboração de Plano Diretor } & Barroso, Luz & Central \\
\hline & $\begin{array}{c}\text { Caxambu, Cruzília, Guaxupé, Minduri, } \\
\text { Ouro Fino, Santa Rita do Sapucaí, São } \\
\text { Sebastião do Paraíso }\end{array}$ & Sul \\
\hline & $\begin{array}{c}\text { Santa Cruz do Escalvado, } \\
\text { Visconde do Rio Branco, Viçosa } \\
\end{array}$ & Zona da Mata \\
\hline Consultoria em planejamento & Mutum & Vale do Rio Doce \\
\hline \multirow{5}{*}{$\begin{array}{l}\text { Elaboração de propostas para a } \\
\text { elaboração de plano diretor/ } \\
\text { legislação urbanística }\end{array}$} & $\begin{array}{l}\text { Baependi, Carrancas, Itanhandu, Carmo } \\
\text { de Minas }\end{array}$ & Sul \\
\hline & Itabirito, Mariana & Região Metropolitana \\
\hline & $\begin{array}{l}\text { Água Boa, Frei Lagonegro, Itabirito, } \\
\text { José Raydan, S. Maria do Suaçuí, S. } \\
\text { José do Maranhão, S. Pedro do Suaçuí }\end{array}$ & Vale do Rio Doce \\
\hline & Tiradentes & Campo das Vertentes \\
\hline & $\begin{array}{c}\text { Alvinópolis, Diogo de Vasconcelos, } \\
\text { Jequeri, Inhapim, Piranga }\end{array}$ & Zona da Mata \\
\hline $\begin{array}{c}\text { Avaliação da aplicação de planos } \\
\text { diretores }\end{array}$ & $\begin{array}{l}\text { Além Paraíba, Leopoldina, Cataguases, } \\
\text { Manhuaçu, Muriaé, Ponte Nova, Ubá, } \\
\text { Santos Dumont, S. João Nepomuceno }\end{array}$ & Zona da Mata \\
\hline \multirow{4}{*}{$\begin{array}{l}\text { Orientação de dissertações de } \\
\text { mestrado }\end{array}$} & Serro & Vale do Mucuri \\
\hline & Ouro Preto & Região Metropolitana \\
\hline & Diamantina & Vale do Mucuri \\
\hline & Itamarati de Minas & Zona da Mata \\
\hline $\begin{array}{c}\text { Monografias produzidas no curso } \\
\text { de especialização }\end{array}$ & $\begin{array}{c}\text { Coimbra, Cajuri, Piedade de Ponte } \\
\text { Nova, Tocantins }\end{array}$ & Zona da Mata \\
\hline Projeto de ampliação urbana & Rio Doce & Zona da Mata \\
\hline $\begin{array}{c}\text { Projetos diversos de pesquisa e } \\
\text { extensão }\end{array}$ & $\begin{array}{l}\text { Araponga, Astolfo Dutra, Bicas, Canãa, } \\
\text { Carangola, Dona Euzébia, Guaraciaba, } \\
\text { Itaverava, Paula Cândido, Pedra do } \\
\text { Anta, Presidente Bernardes, Porto } \\
\text { Firme, Rio Pomba, S. Geraldo, S. } \\
\text { Miguel do Anta, S. Lourenço, Senador } \\
\text { Firmino, Tabuleiro, Teixeiras. }\end{array}$ & Zona da Mata \\
\hline
\end{tabular}

Fonte: Autores, 2014.

Este artigo é amparado por um volume significativo de dados empíricos, resultantes de experiências em ensino, da avaliação de projetos de assessorias na elaboração de planos diretores e de resultados de pesquisas, com foco em pequenas cidades. Uma parte é proveniente das experiências em ensino, observadas através do curso de especialização lato sensu, em planejamento Municipal, em oito turmas entre 1994 e 2004, cujo público alvo foram técnicos 


\section{Revista Nacional de}

atuantes em pequenas e médias cidades oriundos de diferentes regiões de Minas Gerais e até de outros estados. Outra parte procede da avaliação de projetos de extensão, a partir da experiência da coordenação da elaboração de treze planos diretores.

Alguns desses tiveram como objetivo propor caminhos, como a formulação de uma política de desenvolvimento regional (STEPHAN, ARANTES e FIALHO, 2008), e discussões como a auto aplicabilidade maior dos planos (STEPHAN, 2008). Uma terceira fonte decorre dos resultados de pesquisas, a experiência se soma tanto na pesquisa sobre a caracterização dos municípios da microrregião de Viçosa e na avaliação dos processos participativos e da aplicação de planos de dezenas de cidades da Zona da Mata mineira, das regiões Sul, Central e Vale do Rio Doce. Acrescentam-se às três formas anteriores, os projetos de extensão, as palestras realizadas em outras cidades e as visitas técnicas com intenção de formalizar a elaboração de legislação urbanística. Esta última forma é plena de frustradas iniciativas, abortadas pela falta de recursos dos municípios ou por desistências de última hora, por motivos nem sempre explicitados.

\section{As condições das pequenas cidades de Minas Gerais}

O Estado de Minas Gerais possui uma área de 587.000 km2, é dividido em 853 municípios e possuía, em 2011, uma população de 20,3 milhões de habitantes. O mesmo levantamento mostrou o Estado na $23^{\text {a }}$ posição na taxa de crescimento anual do país (IBGE, 2011). Possui um município com mais de 2,3 milhões de habitantes a capital Belo Horizonte, três com população entre 500.000 e 600.000 habitantes (Contagem, Uberlândia e Juiz de Fora), vinte e quatro municípios com população entre 100 e 500 mil habitantes e oitocentos e vinte e quatro municípios com população inferior a 100 mil habitantes, o que representava $96,6 \%$ do número de municípios ${ }^{\text {ii }}$. O grau de urbanização do estado era de $84,4 \% \%$, a região Central apresentava a $1^{a}$ posição com uma taxa de $93,2 \%$, sendo que o Sul de Minas estava 


\section{Revista Nacional de}

em 5o lugar, com $80,60 \%$ e a Zona da Mata em 6o lugar, com 79,8\% (IBGE/Fundação João Pinheiro, 2011). Minas Gerais ocupava, em 2012, o nono lugar no ranking em IDHM no país. É um Estado com desigualdades significativas; sendo as regiões Sul, Centro e Oeste, mais desenvolvidas e as regiões Leste, Nordeste e Norte apresentam indicadores semelhantes aos da região Nordeste do país.

A valorização exacerbada da terra e a possibilidade de ampliação dos patrimônios individuais estimulam a expansão da malha urbana sem conexões com outros bairros, com vias de dimensões mínimas, com o maior número possível de lotes de dimensões mínimas, e com a destinação de áreas institucionais com forma, topografia e localização das piores possíveis. Espaços destinados a áreas verdes e praças se transformam em instrumentos de barganha política e posteriormente são divididos em lotes. Em várias cidades, a infraestrutura viária e de saneamento oferecida pelos loteadores é mínima. A conivência das administrações quando da aprovação dos loteamentos acarreta a sobrecarga posterior da complementação da infraestrutura não implantada, como pavimentação e drenagem, e as consequências de sua falta, com soluções a posteriori de alto custo e complexidade.

Segundo Arantes (2013), a "onda de valorização imobiliária rentista que parece beneficiar a todos, dos grandes proprietários aos pequenos, que vêem seu capitalzinho imobiliário valorizar-se e têm a certeza de que sempre valeu a pena estar ao lado da propriedade privada". Essa valorização da terra cria, nas cidades, independentemente de seu porte, "uma situação desfavorável aos trabalhadores, ampliando a diferença entre renda imobiliária e renda do trabalho (salários)" (ARANTES, 2013, p.8). A especulação imobiliária já é um fenômeno disseminado nas cidades que experimentam um maior crescimento demográfico e especialmente naquelas que receberam campi ou ampliaram o número de cursos universitários tais como Viçosa, Mariana, Ouro Preto, Rio Paranaíba e Diamantina.

Outro aspecto é a forma de ocupação e o uso do solo urbano. Há graves aspectos a serem considerados. Construções à beira dos cursos d'água 


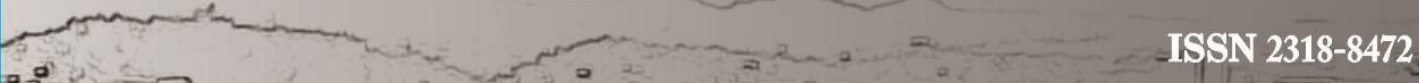

\section{Revista Nacional de Gerenciamento de Cidades}

desrespeitam há décadas as leis federais, além dos problemas de enchentes e desabamentos. Os aspectos ambientais e estéticos vêm sendo alterados profundamente. Um deles é que, nos bairros residenciais, no lugar de edificações unifamiliares com jardins à frente do lote, os afastamentos são preenchidos com garagens, muros e telhados. As ruas, quase sempre arborizadas, onde antes havia casas com jardins e muros com grades, e, de ambientes agradáveis se tornaram vias áridas e desertas que amedrontam os pedestres. As calçadas não possuem continuidade, não possuem acessibilidade. As rampas de automóveis utilizam o espaço que deveria destinado aos passeios públicos e comprometem cada vez mais a acessibilidade.

Figura 2: Inhapim, MG - 24.294 habitantes (IBGE, 2014). Urbanização às margens do curso d' água.

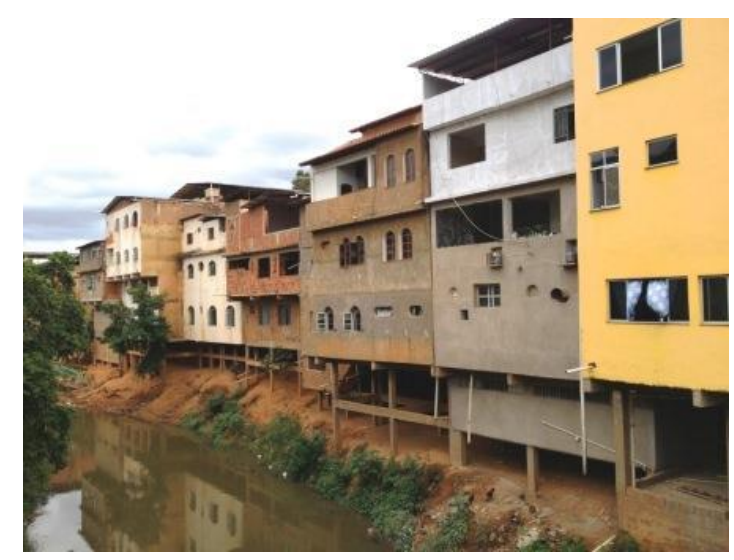

Fonte: Autores, 2013.

No lugar das pequenas edificações, em muitos casos com qualidades de patrimônio histórico, há substituições por edificações de péssima qualidade estética, que ocupam até mais de cem por cento do terreno, com dois ou mais pavimentos e com terraços metálicos utilizados como ambientes de lazer e de serviços. Onde antes havia alinhamento das edificações com a via, surgem massas de edificações com recuos, avanços e afastamentos diversos, sem alinhamento, alterando 


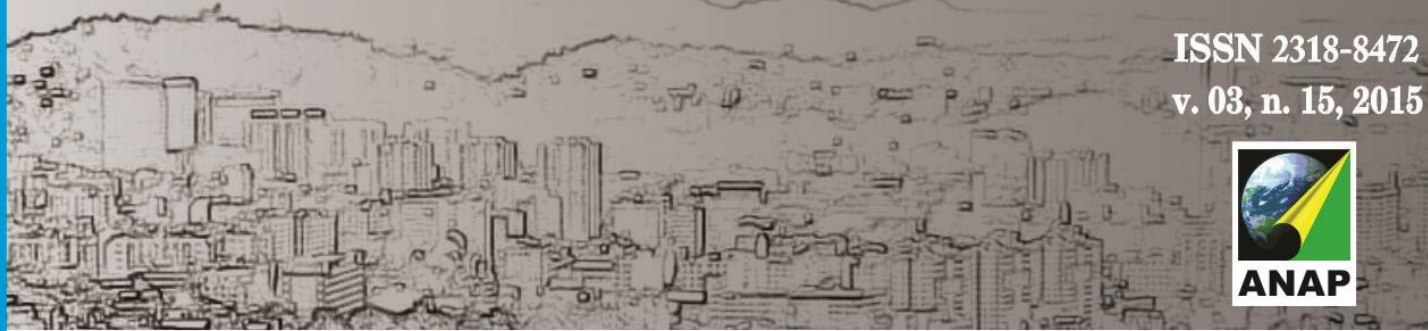

\section{Revista Nacional de} Gerenciamento de Cidades

profundamente uma ordem anterior.

Há o fenômeno da subdivisão dos lotes ou a adição de várias unidades em um, sem afastamentos. Essas formas de ocupação acarretam o avanço de construções por cima das calçadas públicas; a impermeabilização dos lotes; o desmembramento destes em parcelas menores; a construção de várias unidades residenciais dentro de um mesmo lote sem a destinação de vagas de estacionamento; a construção de rampas e degraus nas calçadas; a solução de estacionamentos particulares gerados contando com as vias urbanas.

Há o agravamento de problemas de trânsito e de acessibilidade em várias cidades pequenas, como consequência da falta de planejamento urbano. Nessas cidades, as ruas estreitas, muitas vezes são as rodovias, com mão dupla onde se espremem vagas de estacionamentos, circulam caminhões, surgem engarrafamentos com muita frequência. A partir dos anos 2000 o trânsito passou a ser o maior problema, de acordo com a opinião de prefeitos de cidades com 7, 10, 15 mil habitantes.

Figura 3: Rio Paranaíba, MG - 12.328 habitantes (IBGE, 2014). Rápida expansão urbana sem planejamento, em função da instalação de um campus universitário.

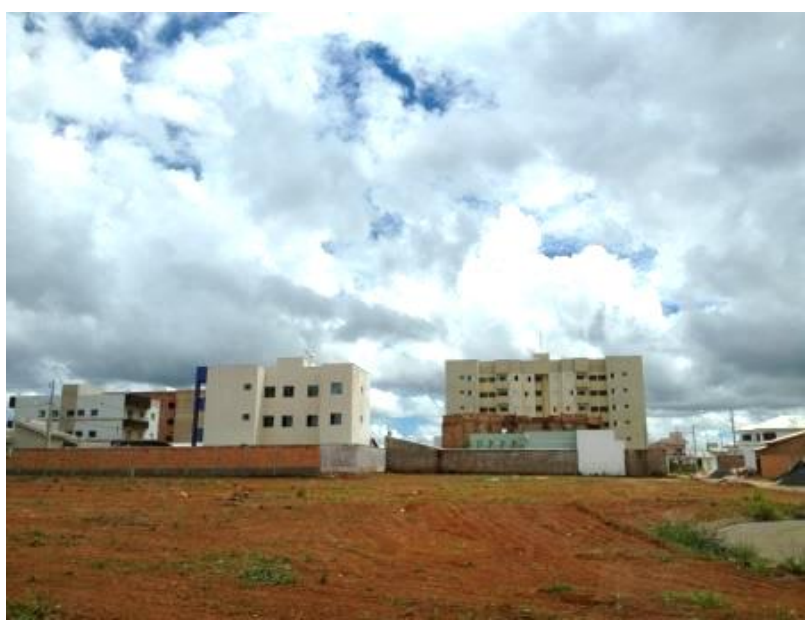

Fonte: Autores, 2013. 


\section{Revista Nacional de}

Por último, nas pequenas cidades, evidencia-se a ampliação da segregação espacial, parte disso em virtude de um planejamento urbano precário. Não há estoque de terras públicas, devido a não exigência de doação de áreas institucionais ao município, quando do parcelamento de terras urbanas. É comum que quadras destinadas a serem praças sejam loteadas e distribuídas ou vendidas. Uma frágil política pública de habitação não define áreas de especial interesse social que não estejam nas franjas da malha urbana, com raras exceções como a pequenina Rio Doceiii. Isso ocorre com a implantação dos conjuntos habitacionais de baixa renda nos locais mais desfavoráveis, afastados, desconectados da malha urbana. Há multiplicação dos condomínios horizontais fechados, em regiões com condições mais favoráveis. Surgem inúmeros granjeamentos nas áreas rurais e loteamentos em áreas rurais, como é o caso de Viçosa. Alguns loteamentos em áreas rurais são permitidos por alterações na legislação municipal. Os agentes desses processos são os atuantes no mercado imobiliário - construtores, incorporadores, corretores, cartórios e advogados - com uma conveniente negligência do poder executivo com os aspectos legais.

Este é um quadro típico de parte significativa das pequenas cidades de Minas Gerais, um quadro complexo e sério, pois, se esse persistir, a qualidade de vida continuará a deteriorar-se. Constata-se que não há sinais significativos de esforços para mudar o quadro, a não ser as exigências para elaboração de Planos Diretores, Planos de Habitação, Saneamento e Mobilidade para os municípios com população superior a vinte mil habitantes. O planejamento urbano, ou não existe, ou onde há um mínimo de estrutura, não atinge a devida importância, logo, as soluções para os problemas são postergadas. O planejamento urbano não é um processo tecnicamente construído mas, um objeto de interesse dos loteadores e dos políticos.

\section{Estrutura de planejamento e gestão urbanos em cidades mineiras}

Nas pequenas cidades, as estruturas de planejamento e gestão urbanos ${ }^{\text {iv }}$ são 


\section{Revista Nacional de}

insipientes. No entanto, todas são dependentes do interesse político, que geralmente ignora os critérios legais e técnicos. Não há, na maioria das cidades pequenas, nos quadros funcionais, técnicos - arquitetos e urbanistas ou engenheiros civis - sequer para analisar e aprovar projetos de construção. Embora algumas das cidades de maior porte - ou seja, aquelas com mais de trinta ou quarenta mil habitantes - possuam algum órgão com função de lidar com algum planejamento urbano. Existe em comum a sobrecarga de trabalho focado apenas na análise e aprovação dos projetos e a pouca experiência em administrar o crescimento urbano e em desenvolver projetos, fazer valer a legislação urbanística ou fiscalizar as construções. A fiscalização é um processo limitado pela escassez de recursos humanos e de infraestrutura física mínima (ambiente de trabalho, veículo para fiscalização etc.). A fiscalização funciona apenas à base de denúncias. Quanto menor a cidade mais dependente ela será de critérios ligados às relações interpessoais e político-partidárias. Os municípios menores possuem um aparato legal restrito e desatualizado, com o predomínio de Códigos de Posturas com mais de 30 anos, por exemplo, enquanto que nos municípios maiores a legislação existe, no entanto encontra dificuldades técnicas ou desinteresse político em sua aplicação. Considerando que o plano diretor participativo foi identificado como o principal instrumento da política urbana definida pelo Estatuto da Cidade, cabe mencionar que, em uma avaliação dos planos municipais brasileiros aprovados, em pesquisa realizada em 2011, pelo Observatório das Metrópoles ${ }^{v}$, os resultados apresentados foram considerados, em geral, desanimadores. Pesquisas específicas em cidades mineiras nos trazem resultados semelhantes (STEPHAN 2006, STEPHAN e ROCHA, 2008 e STEPHAN, 2009). 
Revista Nacional de Gerenciamento de Cidades

Figura 4: Viçosa, MG - 76.000 habitantes (IBGE, 2014). Vigoroso processo de verticalização e invasão de áreas de preservação permanente.

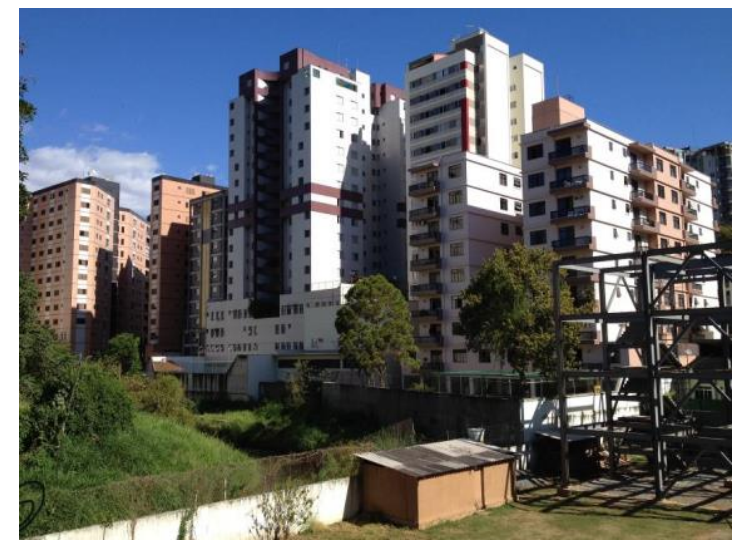

Fonte: Autores, 2014.

Em Minas Gerais, cerca de 160 planos diretores participativos foram elaborados desde 2006. As cidades com mais de vinte mil habitantes e outras como as que fazem parte de associações, como a Associação dos municípios do lago de Furnas (Alago), elaboraram seus planos diretores em 2006. Outros requisitos tornaram obrigatória a elaboração dos planos, como nas cidades de interesse turístico, como os que fazem parte da Estrada Real, embora diversos municípios permaneçam sem cumprir a regra. Cidades históricas permanecem, em 2015, sem planos diretores. O quadro geral, após alguns anos, é que os planos foram aprovados nas casas legislativas locais sem maiores discussões. As exigências para a adoção de planos produziram planos diretores elaborados com diversos problemas, como aqueles elaborados por meio de cópias e com baixo grau de participação popular (STEPHAN, ROCHA, 2009).

A última exigência legal trata da obrigatoriedade da elaboração dos planos de mobilidade, com o prazo de aprovação em abril de 2015. Um denominador comum para os planos diretores - o da aprovação sem implementação, ou da postergação de sua elaboração - possivelmente se repetirá com mais essa exigência. Análises da aplicação de planos diretores de municípios de diversas regiões de Minas Gerais (STEPHAN, 2009), revelaram que os planos possuem um percentual reduzido de 


\section{Revista Nacional de}

dispositivos autoaplicáveis e um grau de aplicação muito baixo. Avaliações permitem afirmar que os planos foram parcialmente aplicados, ou seja, tiveram alguns dispositivos aplicados quando se tratavam de obras que seriam realizadas independentemente da existência dos planos. Os planos prescrevem regulamentações com prazos posteriores à sua aprovação, com alto índice de não cumprimento. Dos dispositivos relacionados ao ordenamento territorial e ao uso do solo, tudo que poderia atrapalhar os interesses do mercado imobiliário ou de políticos - como índices urbanísticos e dimensões mínimas de vias e lotes - é alterado de forma pontual.

Dos instrumentos previstos no Estatuto da Cidade, nada foi aplicado, com exceção da exigência do Estudo de Impacto de Vizinhança, adotado e cobrado em alguns municípios. Da criação e permanência de um sistema de acompanhamento do plano - órgão gestor e conselho da cidade - os resultados foram de raro sucesso, como em São Sebastião do Paraíso, no caso do órgão gestor e Ponte Nova, no caso do conselho da cidade, embora este tenha funcionado com interrupções.

Quanto à democratização do acesso à terra urbanizada e quanto à promoção do acesso à moradia, os obstáculos políticos parecem ter preponderado. Esperavase a regulamentação de instrumentos presentes nos planos, que propiciassem a ocupação de vazios urbanos, a regularização fundiária e a captura e redistribuição da valorização dos terrenos gerada pelos investimentos com recursos públicos. Era importante a definição e demarcação das Zonas de Especial Interesse Social ZEIS, especialmente com a definição delas em vazios urbanos. Isso não ocorreu em nenhuma cidade conhecida.

Não há condições para que os municípios desenvolvam uma estrutura mínima de planejamento. Não há ambiente para o planejamento, para a criatividade, não são elaborados projetos para buscar recursos. Municípios de pequeno porte demográfico dependem da contratação de projetos, de elevado custo, através da iniciativa privada, e não é incomum ficarem dependentes de empresas que atuam 


\section{Revista Nacional de}

Gerenciamento de Cidades

como intermediários para a obtenção de recursos.

\section{Conclusão: Ousando apontar caminhos}

Para aprofundar na busca de caminhos são necessários mais estudos aprofundados e específicos que este cenário apresentado. No entanto, é possível vislumbrar possíveis caminhos. Um potencial ainda a ser desenvolvido é o do compartilhamento de recursos humanos, especialmente os ligados à Arquitetura e Urbanismo. Há outras possibilidades a serem desenvolvidas. Recursos para capacitação dos técnicos municipais e contratação de profissionais da área de Arquitetura e Urbanismo que poderão ser efetivados por meio de consórcios microrregionais ou de outras formas de parcerias entre dois ou mais municípios, de maneira a amortizar os custos fixos e os investimentos sobre uma base maior de usuários, reduzindo o custo unitário da produção e distribuição dos serviços.

Desde os anos 1990, os consórcios de cidades foram criados como uma forma aprimorada de federalismo. Para Nassif (2013), falta discutir, na reforma política, os arranjos federativos e, neles, o instituto dos consórcios. Esses representariam um avanço na governança, já que os consórcios são constituídos por prefeituras, cada uma compartilhando sua gestão com a sociedade civil e, pelo fato de ser uma gestão compartilhada, garantiria a continuidade das políticas independentemente do prefeito e dos partidos (NASSIF, 2013).

Toda cidade deveria possuir uma legislação urbanística aplicada e atualizada, uma estrutura administrativa mínima e eficiente, um cadastro técnico atualizado e uma estrutura de fiscalização de obras e posturas. Este conjunto de requisitos é citado por diversos autores (MARICATO, 2000, SOUZA, 2002). No entanto, solucionar a falta de estrutura de planejamento urbano em pequenas cidades é um desafio. Por mais simples que seja, é um sistema que demanda, acima de tudo, interesse político mas, carece também do interesse de participação da população. Dos lados técnicos e financeiros, o município necessita de recursos para 


\section{Revista Nacional de Gerenciamento de Cidades}

elaboração, manutenção e atualização de uma estrutura de planejamento. Os municípios, nestas primeiras décadas do século XXI, não sairão sem a participação dos outros níveis de Estado. Não se pode viver na dependência de se obterem recursos via emendas parlamentares ou na irregularidade da oferta da modalidade de seleção pública.

O ensino superior, presente em muitas pequenas cidades mineiras, possui um potencial a ser desenvolvido, no ensino, pesquisa e extensão. Ele pode ser ofertado na base da formação dos cidadãos, na capacitação técnica, no desenvolvimento de pesquisas e na realização de convênios. Existe em Minas Gerais um enorme potencial a ser desenvolvido pelas universidades e institutos federais, existentes em grande número e distribuição geográfica favorável. São trinta e dois cursos de Arquitetura e Urbanismo em dezoito cidades mineiras. São onze universidades federais e vários campi distribuídos em todo o Estado. Algumas instituições desenvolvem assessorias na elaboração de planos diretores como a Universidade Federal de Viçosa (UFV), Universidade Federal de Minas Gerais (UFMG) e Universidade Federal de Juiz de Fora (UFJF), e podem oferecer cursos de curta duração em capacitação e cursos lato sensu e strictu sensu na área de planejamento e gestão municipal. 


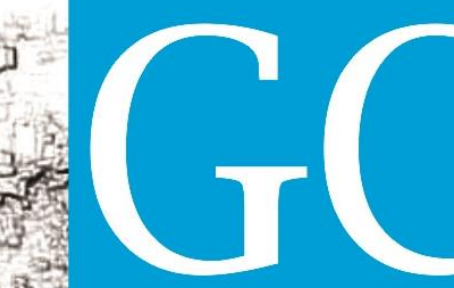

Revista Nacional de Gerenciamento de Cidades

Figura 5: Minas Gerais com destaque para os municípios com campi de universidades federais e estaduais.

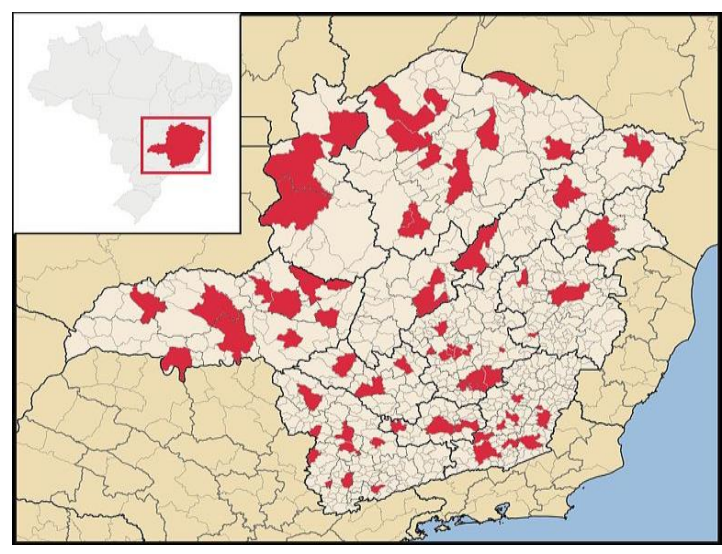

Fonte: Wikipedia Commons.

A Lei de Assistência Técnica gratuita (Lei № 11.888 / 2008) criou serviços permanentes e gratuitos de assistência técnica nas áreas de Engenharia e Arquitetura Públicas e vislumbra a possibilidade de criar programas de residência acadêmica em Arquitetura, Urbanismo ou Engenharia ou em programas de extensão universitária, por meio de escritórios-modelos ou escritórios públicos com atuação na área. Até o final de 2013, a modalidade da residência acadêmica foi criada apenas na Universidade Federal da Bahia (UFBA) e os programas de Engenharia e Arquitetura Públicas permaneceram inatos ou inertes. Viçosa, por exemplo, já aprovou sua lei de assistência técnica, embora não a tenham colocado em prática.

Para desenvolver o processo do planejamento municipal e regional, é necessário identificar possíveis parceiros, como o Serviço Brasileiro de Apoio às Micro e Pequenas Empresas (SEBRAE) vi. Suas áreas de atuação não lidam diretamente com a capacidade de planejamento e gestão dos municípios. No entanto, para criar ambientes favoráveis para o desenvolvimento sustentável dos pequenos negócios e do empreendedorismo, é necessário existir um ambiente favorável em sua base territorial, que é a cidade. Uma vez que as empresas se localizam na cidade, seu sucesso depende, em parte, da existência de uma 


\section{Revista Nacional de}

Gerenciamento de Cidades

estrutura minimamente organizada para se desenvolver. Preparar a base local para o desenvolvimento dos negócios, é uma área na qual o órgão pode vir a atuar, em forma de parcerias. Apesar da limitada capacidade institucional, da restrição dos gastos e da precária estrutura do poder local, há perspectivas, há alternativas para tão complexo conjunto de cidades. É fundamental transformar o potencial em energia cinética, através da educação e da conscientização dos governantes e dos governados.

\section{Referências Bibliográficas}

ARANTES, Pedro. Da (Anti) Reforma Urbana brasileira a um novo ciclo de lutas nas cidades. Correio da Cidadania, 13 de nov. 2013. Disponível em: http://www.correiocidadania.com.br/index.php?option=com_content\&view=article\&id=9047\%3Asubma nchete091113\&catid=72\%3Aimagens-rolantes\&. Acesso em 20 mai 2015.

BRASIL, República Federativa. Lei no 11.888, de 24 de dezembro de 2008, Assegura às famílias de baixa renda assistência técnica pública e gratuita para o projeto e a construção de habitação de interesse social e altera a Lei no 11.124, de 16 de junho de 2005.

BRASIL, Ministério das Cidades. Plano Diretor Participativo: guia para elaboração para municípios e cidadãos. $3^{\underline{a}}$ ed./ Coordenação geral de Raquel Rolnik e Otile Macedo pinheiro Brasília: ministério das Cidades; CONFEA, 2008.

CORREAA, Roberto Lobato. As pequenas cidades na confluência do urbano e do rural. GEOUSP - Espaço e Tempo, São Paulo, no 30, 2011, p. 5-12.

ENDLICH, Ângela Maria. Pensando os papéis e significados das pequenas cidades. UNESP, 2006.

MARICATO, Ermínia. Brasil, Cidades: alternativas para a crise urbana. Petrópolis: Vozes, 2001.

NASSIF, Luis. Hora de repensar os consórcios municipais, 28/09/2013. Disponível em: <http://jornalggn.com.br/noticia/hora-de-repensar-os-consorcios-municipais> Acesso em 03 mar 2014.

RATTNER, in: ACSELRAD, Henri (Org.). A duração das cidades. RJ: Lamparina, 2009.

SOUZA, Marcelo Lopes de. Mudar a Cidade: uma introdução crítica ao planejamento e à gestão urbanos. Rio de Janeiro: Bertrand Brasil, 2002. 556 p.

STEPHAN, Ítalo I. C. "Plano diretor de Viçosa: avanços e limitações". Vitruvius: Arquitextos 78, Texto especial 393, nov. 2006. 


\section{Revista Nacional de}

Gerenciamento de Cidades

; ARANTES, Paulo Tadeu Leite; FIALHO, Beatriz Campos; REIS, Luiz Fernando; LOPES, Camila de Souza. Participação popular e cooperação intermunicipal: Os Planos Diretores de Cruzília e Minduri MG. Arquitextos, São Paulo, ano 09, n. 100.03, Vitruvius, set. 2008.

; REIS, Luiz. F. "Revisão do Plano Diretor de Viçosa: participação popular e auto aplicabilidade". Risco. São Carlos, v.6, p.84 - 93, 2007.

; ROCHA, Rodrigo F. Planos diretores: que participação é essa? Revista Tecnológica, Edição Especial ENTECA 2008, p. 107-116, 2009, Disponível em:http://periodicos.uem.br/ojs/index.php/RevTecnol/article/viewFile/8701/5176. Acesso em 03 abr 2015.

\footnotetext{
"Planos Diretores em Minas Gerais: vinte anos de exigência constitucional”. Revista $\overline{\text { Risco }} \mathrm{n}^{\mathrm{0}}$ 10. São Carlos, p. 46-56, 2009. Disponível em http://arquitetura.eesc.usp.br/revista_risco/Risco10-pdf/02_art05_risco10.pdf. Acesso em 20 mai 2015.
}

VAINER, Carlos. Quando a cidade vai às ruas. In: Cidades Rebeldes, Passe livre e as manifestações que tomaram as ruas do Brasil. MARICATO, Ermínia [et. al.], São Paulo: Boitempo, 2013, p. 36-40.

WANDERLEY, Maria de Nazaré Baudel. Urbanização e ruralidade: relações entre a pequena cidade e o mundo rural. Estudo preliminar sobre os pequenos municípios em Pernambuco, Recife, 2001. Disponível em: <http://www.fundaj.gov.br/observanordeste/obed001f.html>. Acesso em 04 nov 2011.

i Um dispositivo autoaplicável é aquele que não precisa ser regulamentado, tem aplicação imediata.

ii Fontes: IBGE e Mercado Comum, jan./fev. 2014.

iii Rio Doce, a 222 km de Belo Horizonte, 2.468 habitantes (2010), 1.653 na área urbana. Possui plano diretor. Todas as residências recebem água tratada pela rede pública. Todas possuem energia elétrica. A cidade conta com Estação de Tratamento de Esgoto (ETE) e uma usina de tratamento e Compostagem de Lixo. A política municipal de habitação proporcionou casas espalhadas na malha urbana e ainda acrescentou laje e varanda anexa à cozinha. Em 2012 inaugurou uma área de expansão urbana, promovida pelo poder público, com lotes ara venda, lotes populares, praça, creche e lotes para a implantação de indústrias não incômodas.

iv Entende-se como estrutura de planejamento e gestão urbanos: 1. Aparato legal - legislação urbanística (plano diretor e leis correlatas). 2. Estrutura administrativa (departamento ou secretaria), responsável pela análise e aprovação de projetos de arquitetura e de parcelamento do solo, inclui cadastro municipal e a estrutura física e de recursos humanos e fiscalização.

${ }^{v}$ Em: http://www.observatoriodasmetropoles.net.

vi. Seu papel é o de criar condições para estimular o empreendedorismo e possibilitar a competitividade e a sustentabilidade dos empreendimentos de micro e pequeno portes no país. 